\title{
Suicídio de agricultores no Rio Grande do Norte: compreensão fenomenológica preliminar dos aspectos existenciais
}

Farmer's suicide in Rio Grande do Norte: a phenomenological preliminary understanding of its existential aspects

Suicidio de agricultores en Rio Grande do Norte: comprensión fenomenológica preliminar de los aspectos existenciales

\author{
Elza Dutra* \\ Marcelo Vial Roehe
}

\begin{abstract}
Resumo
Este artigo apresenta dados de pesquisa realizada com o objetivo de compreender os significados existenciais do suicídio de agricultores no Rio Grande do Norte, Estado da Região Nordeste. Baseou-se em pesquisa anterior, que constatou um índice significativo de suicídios cometidos por agricultores em alguns municípios potiguares. Nesta pesquisa, de natureza qualitativa e de inspiração fenomenológica, foram entrevistados familiares dos suicidas e pessoas residentes nos cinco municípios que apresentaram as maiores taxas de suicídio entre agricultores. As 20 pessoas colaboradoras da pesquisa foram selecionadas intencionalmente, de acordo com os objetivos do estudo. Os depoimentos, em forma de narrativas, foram gravados, transcritos e literalizados. Posteriormente, foram compreendidos com uma abordagem baseada na analítica existencial, do filósofo alemão Martin Heidegger, que aponta para a limitação das possibilidades de ser-no-mundo e o peso de ser o que não se quer ser.
\end{abstract}

Palavras-chave: Suicídio. Rio Grande do Norte. Psicologia fenomenológico-existencial. Pesquisa qualitativa.

\begin{abstract}
The article presents findings concerning a study that aims to understand farmers' suicide existential aspects from a phenomenological standpoint. It is based on a previous research whose findings featured high suicide
\end{abstract}

\footnotetext{
Doutora em Psicologia pela USP, professora no Programa de Pós-Graduação em Psicologia da Universidade Federal do Rio Grande do Norte.

** Doutorando em Psicologia pela Universidade Federal do Rio Grande do Norte. Endereço: Universidade Federal do Rio Grande do Norte, Centro de Ciências Humanas, Letras e Artes, Departamento de Psicologia. Campus Universitário, s/ $n^{\circ}$ - Lagoa Nova, Natal-RN. CEP: 59075-970.
} 
rates between poor farmers in Rio Grande do Norte countryside. Twenty people from the five cities with highest suicide rates in Brazilian state Rio Grande do Norte were interviewed. The subjects are relatives and friends of suicide victims whose interviews were recorded and transcribed in narrative form. Based on German philosopher Martin Heidegger's Existential Analytic, conclusions pointed to limits imposed upon the possibilities inherent in being-in-the-world and the burden of an unfulfilled being.

Keywords: Suicide. Rio Grande do Norte. Existential-phenomenological psychology. Qualitative research.

\section{Resumen}

El artículo presenta conclusiones acerca de un estudio que pretende comprender los significados existenciales del suicidio de agricultores en Rio Grande do Norte, Estado de la Región Noreste de Brasil. Se basó en un estudio anterior que constató un índice significativo de suicidios cometidos por agricultores en algunos municipios de la región. En este estudio, de naturaleza cualitativa y de inspiración fenomenológica, se entrevistó a familiares de los suicidas y a personas residentes en los cinco municipios que presentaron los más altos índices de suicidio de agricultores. Las 20 personas participantes del estudio fueron seleccionadas intencionalmente de acuerdo con los objetivos del estudio. Las entrevistas fueron registradas y transcritas en forma de narrativa. Posteriormente fueron interpretadas a partir de un planteamiento basado en la analítica existencial del filósofo alemán Martin Heidegger, que muestra una limitación de las posibilidades de ser-en-el-mundo y el peso de ser lo que no se quiere ser.

Palabras clave: Suicidio. Rio Grande do Norte. Psicología fenomenológica-existencial. Investigación cualitativa.

\section{Apresentação ${ }^{1}$}

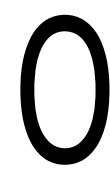

suicídio é um fenômeno que tem sido abordado de diversas maneiras e sob vários ângulos ao longo da história da humanidade. Dependendo do contexto histórico e cultural em que ocorre, é encarado sob diversos olhares. Ao longo da história das civilizaçóes, esse ato tem sido considerado altruísta ou indicador de insanidade. Foi alvo tanto de condenação como de absolvição e, muitas vezes, a família do suicida era punida por esse ato (Alvares,

\footnotetext{
Pesquisa realizada com o apoio do CNPq.
} 
1999). Também nas artes, o suicídio se tornou um evento clássico, como mostram Silva et al. (2006) em seu estudo sobre a presença de personagens suicidas na ópera.

Embora tais constatações possam denotar valorização da questão do suicídio, ainda não se pode afirmar com convicção que este tenha merecido tratamento condizente à sua importância. Tal opinião é compartilhada por alguns estudiosos, como Cassorla (1991) e Menninger (1970). Este último afirma que "o suicídio continua a atrair muito menos atenção do que sua seriedade e prevalência parecem justificar" (Menninger, 1970, p. 28).

Muitos estudos epidemiológicos, além daqueles de natureza sociológica, psiquiátrica e psicológica, já foram empreendidos acerca do suicídio (Qin, Agerbo \& Mortensen, 2005; Mello-Santos, Bertolote \& Wang, 2005; Bertolote \& Fleischmann, 2002). Durkheim (1992), no século XIX, publicou um amplo trabalho, no qual é apresentado um retrato detalhado do suicídio na Europa de então. Naquela época, o autor já desenvolvia importantes reflexões acerca da intencionalidade e das implicações sociais do suicídio, questóes que se mantêm pertinentes nos dias atuais. Um exemplo disso é a afirmação de que "cada sociedade tem, portanto, em cada momento da sua história, uma aptidão definida para o suicídio" (Durkheim, 1992, p.14). Assim, os estudos epidemiológicos, tão comuns quando se trata do fenômeno do suicídio, ensejam uma visão dos aspectos sociodemográficos da população estudada, favorecendo, desse modo, uma visão realista e pertinente do meio onde o fenômeno ocorreu.

Numa série de documentos, a World Health Organization (Organização Mundial de Saúde) reconhece e alerta para a gravidade da questão do suicídio (World Health Organization, 2013). De maneira geral, esses estudos confirmam algumas tendências e características presentes na população mundial. Sabe-se, por exemplo, que o sexo masculino comete mais suicídio do que o feminino, entretanto são as mulheres que tentam o suicídio com mais frequência; para cada suicídio, há, em média, 5 ou 6 pessoas próximas ao falecido que sofrem consequências psicológicas, sociais e econômicas; e, ainda, nos últimos 45 anos, a mortalidade global por suicídio vem migrando em participação percentual do grupo dos mais idosos para o de indivíduos mais jovens (15 a 45 anos). No Brasil, conforme informação do Ministério da Saúde (Brasil, 2006), a taxa de suicídio é baixa, tendo variado entre 3,9 e 4,5 por 100 mil habitantes a cada ano entre 1994 e 2004.

$\mathrm{Na}$ Região Nordeste, poucos estudos têm sido desenvolvidos sobre o fenômeno do suicídio. Entre eles, encontra-se o de Dutra (1997), mostrando 
que, entre as 567 ocorrências de suicídios registrados em 11 anos (de 1985 a 1996), no Rio Grande do Norte, 16,2\% deles foram cometidos por agricultores do interior do Estado. Tal evidência estimulou a necessidade de aprofundar o conhecimento relativo a esse fato, principalmente quando pensamos nas limitantes características sociais e geográficas da Região Nordeste e nos interrogamos sobre a importância que essas condições teriam no desencadeamento do fenômeno (Dutra, 2010).

\section{O enfoque fenomenológico-existencial na realização do estudo}

Tendo em vista os dados obtidos no trabalho de 1997, elaborou-se uma estratégia de pesquisa qualitativo-fenomenológica, a fim de compreender aspectos existenciais que poderiam estar relacionados ao fenômeno do suicídio de agricultores. A compreensão a que o trabalho fenomenológico visa diz respeito a apreender os significados que o entrevistado atribui ao fenômeno em questão e colocá-los na perspectiva do conhecimento psicológico de orientação heideggeriana (Roehe, 2012). A tradição psicológica de orientação heideggeriana remonta aos anos 40 do século passado, com o trabalho do psiquiatra suíço Ludwig Binswanger (Halling \& Nill, 1995). Outro psiquiatra suíço, Medard Boss, trabalhou contando com a colaboração do próprio Heidegger (Boss, 1979).

De acordo com Heidegger (2006), o ser humano (Dasein, conforme o filósofo) sempre já se orienta numa determinada compreensão do seu contexto, numa familiaridade com o que lhe é próximo. Não se trata, porém, de algo racionalizado ou intelectualizado, mas sim vago, mediano e (sempre) vinculado a um humor.

O humor indica como alguém está, como vai. $\mathrm{O}$ humor influencia naquilo que se percebe e como se percebe: pode-se estar atento a muitas coisas ou a poucas, acessível a determinados temas e desligado de outros, sensível a alguns objetos e pessoas e insensível a outros. O ser humano entra em sintonia com aquilo que mais se aproxima do seu humor (Roehe, 2012).

O trabalho fenomenológico de base heideggeriana em Psicologia pretende, portanto, compreender explícita e formalmente aquilo que medianamente, vagamente, informalmente já é compreendido. Consequentemente, a compreensão não é um privilégio do pesquisador diante do entrevistado. Ambos sempre se orientam conforme compreensões próprias na forma de uma estrutura prévia da compreensão (Heidegger, 2006). Assim, num contexto médico, o suicídio poderá ser compreendido como sintoma de alguma doença psiquiátrica, num outro contexto, psicológico, por exemplo, 
poderá ser compreendido como ato de desespero diante de uma situação ruim insolúvel, por sua vez, o contexto religioso poderá considerar o suicídio como um pecado.

Pensar nos aspectos existenciais do fenômeno do suicídio implica considerar que qualquer fenômeno humano se origina nas características do modo de ser do homem. $\mathrm{Na}$ analítica existencial de Heidegger (2006), essas características são chamadas de existenciais. Para Heidegger (2006), o ser humano acontece como relação com o próprio ser, a qual ocorre no mundo, que é onde se desenvolve a ação humana, na forma de escolhas diante de possibilidades de ser. A morte é a possibilidade mais própria: é de si mesmo para si mesmo. Conforme Heidegger (2006), a morte não é um ponto final ao qual se deve chegar: o ser humano vivencia seu tempo de vida como finitude, como "ser para a morte".

Ao se questionar alguém sobre o problema do suicídio, está-se procurando uma aproximação da experiência de ser-no-mundo (Heidegger, 2006) através não daquele que cometeu o ato, mas dos que com ele se vincularam e que habitam o mesmo mundo geográfico, social e cultural. Sendo-no-mundo é como o homem existe, já sempre envolvido em vínculos existenciais (relativos ao seu modo de ser) com os outros seres humanos e com os demais entes, biológicos ou não. Heidegger afirma:

A expressão composta "ser-no-mundo", já na sua cunhagem, mostra que pretende referir-se a um fenômeno de unidade. Devese considerar esse primeiro achado em seu todo. A impossibilidade de dissolvê-la em elementos, que podem ser posteriormente compostos, não exclui a multiplicidade de momentos estruturais que compõem essa constituição (Heidegger, 2006, p. 98-99).

Por intermédio dos relatos dos colaboradores da pesquisa, pretendeuse conhecer os significados que permeiam o suicídio de agricultores numa determinada família e comunidade, na tentativa de compreender possíveis motivações que levaram aqueles agricultores a cometer $\mathrm{o}$ ato.

$\mathrm{Na}$ verdade, o estudo se refere ao sofrimento. O sofrimento dos que cometem suicídio e o dos que lhes são próximos e vivenciam a perda. Assim, o estudo se desenvolveu tendo como horizonte o sofrimento que acompanha o fenômeno do suicídio. A esse respeito, Dutra escreve:

[...] precisamos refletir mais criticamente sobre o sofrimento psíquico nos dias atuais e como o homem desse tempo constrói as suas relações de sentido. Como as condições econômicas, históricas, sociais e culturais influenciam e participam do 
processo de construção das subjetividades e, consequentemente, dos sintomas, estes entendidos enquanto expressão de sofrimento (Dutra, 2008, p. 224).

\section{Coleta de dados}

A estratégia metodológica utilizada para a coleta de dados foi a narrativa, tal como proposta por Dutra (2002) e Schmidt (1990). Trata-se de uma entrevista semiaberta, iniciada com uma pergunta disparadora que permita ao entrevistado iniciar, em seus próprios termos, uma fala sobre o fenômeno questionado. Nesse caso, perguntamos o que a pessoa podia nos dizer sobre a experiência de perder um familiar por suicídio. As entrevistas foram gravadas, transcritas e depois literalizadas. Literalizar (Dutra, 2002; Schmidt, 1990; Maux, 2008) significa, sem que se altere o conteúdo da narrativa, dar um formato literário, narrativo, à fala do entrevistado. Posteriormente, é feita uma leitura detalhada da narrativa, visando a identificar falas e significados que revelem características da vivência questionada. Esse procedimento dará origem, então, a alguns núcleos de sentido que serão interpretados fenomenologicamente, num diálogo entre as narrativas, a relação dos pesquisadores com os colaboradores (Dutra, 2002), o referencial teórico e estudos outros com temática afim.

A pesquisa de campo se desenvolveu em cinco municípios, selecionados entre aqueles que apresentaram maiores taxas de suicídio de agricultores, tal como evidenciado na pesquisa citada acima (Dutra, 1997). No total, 20 pessoas foram entrevistadas, entre familiares de suicidas e residentes das cidades. Os familiares foram selecionados com base nos dados coletados no Itep (Instituto Técnico de Polícia), onde a pesquisa anterior foi realizada. Ao localizarmos o endereço da família no Município, nós nos apresentávamos, esclarecíamos sobre os objetivos do estudo e solicitávamos a assinatura do termo de consentimento livre e esclarecido.

\section{Compreensão dos dados}

Com base nas manifestações dos entrevistados, percebe-se que, mesmo na surpresa diante do ato e no desconhecimento de seus motivos, ainda assim há uma informação ou uma suposição sobre o que levou a pessoa ao suicídio:

Ninguém sabe por que foi... Aconteceu isso... E até hoje a gente num tá sabendo... A gente num tá sabendo por que foi. O rapaz era muito calmo, ele num dizia nada, agora ele vinha meio triste com essa dor no braço, só se queixando com uma dor... (Irmã de um suicida) 
A pessoa fazer uma coisa dessa, né? E eu sei lá... Pela caridade. Só sendo uma pessoa com muito aperreio... Aperreada. Querendo que o aperreio acabasse. (Francisca, 39 anos, moradora de um sítio)

Por outro lado, outro entrevistado avança em análises sociais tipicamente brasileiras, no entanto não usualmente associadas ao suicídio:

A discriminação é um dos motivos que levam alguém a se matar. A pessoa ser discriminada pela sociedade quando você tenta conseguir um negócio que não consegue. Acredito que isso pode ser um grande passo para ficar psicologicamente abalado. (Estudante, 21 anos)

[...] Nós não temos segurança hoje. Você que rouba um carro... não é preso... você que rouba uma bicicleta é preso... isso não tem cabimento. Muitas coisas erradas e desiguais que existe... isso você sabe que cria uma revolta na comunidade. Às vezes, uma pessoa que merece ser presa, não é... (Estudante, 21 anos)

Manifestações dos colaboradores do estudo revelam o entendimento de que as condições de vida nos locais visitados são muito limitadoras e frustrantes, permitindo que se pense, em leitura psicológica, em um não-querer-ser-nomundo:

Aqui não tem emprego, não... O meu filho reclamava... Se a pessoa quiser trabalhar, vá arrumar um serviço em Natal... São Paulo... Goiás... Era o que ele falava... (Antônio, 56 anos, agricultor, pai de um suicida)

Trabalho aqui na plantação nossa. Vivemos dessa plantação... De milho... e feijāo. Oalgodão não dá mais... O bicudo acabou. Recebemos aposentadoria... Não temos televisão... Temos rádio... Passamos o dia assim... plantando... catando... debulhando... Conversando com os vizinhos... chega os vizinhos... Ali tem uma mulher que tem dia que ela passa o dia todinho aqui... só pensando na vida mesmo. A vida sofrida... vida sofrida... é... assim... a pessoa viver no sitio trabalhando... a produção esperando por Deus mandar... Ai meu Deus... mas ele só dá as coisinhas fraquinhas assim mesmo... Quando acontece uma seca dessa... num tempo bom, é só chegar a chuva... Nós torcemos pra que Deus mande, né? Ficamos esperando a chuva... quando for o mês que entra vai chover... Quando passa um dia e não chove... No outro chove... ai passa não chove... nós vivemos assim... (Antônio, 56 anos, agricultor, pai de um suicida)

Aí, meu Deus, é um sofrimento... um sofrimento e grande. Uma pessoa viver aqui, meu Deus! Sei lá... num tem um trabalho... num tem nada para gente... é ruim demais... (Antônio, 56 anos, agricultor, pai de um suicida) 
A vida dos jovens aqui é assim... eles não fazem nada... Nada... vão pro colégio... e pronto. Durante o dia, sai pro colégio e fica assim mesmo... sem ter o que fazer.. porque não tem o que fazer de jeito nenhum... Sobre a minha vida... sei lá, minha filha... com um rebanho de filho, eu sofro muito... sem ter condiçôes... penso que é um sofrimento e grande... Tinha vontade de sair daqui... de mudar de vida... Ave Maria... eu tinha e muito. Sair daqui para morar não sei onde... eu tenho para mim que, se eu saisse daqui para morar em outro canto, minha vida, para mim, era melhor. Porque, pelo menos, a pessoa podia arrumar... sei lá... um trabalho... uma coisa... Aqui não tem trabalho não... Os filhos... jovens... os rapazes e moças... pensam em sair daqui... Eu não sei o que é que eles pensam em fazer da vida... (Francisca, 39 anos, moradora de um sítio)

Esses excertos das entrevistas possibilitam uma reflexão inicial sobre a questão do suicídio com base no trabalho do filósofo alemão Martin Heidegger (1889-1976). Cabe ressaltar que os autores não dispõem de informações a respeito da condição de saúde dos suicidas e somente caracterizam o fenômeno em diálogo com ideias de Heidegger.

$\mathrm{O}$ ato de suicidar-se aparece como uma recusa ao que Heidegger (2006) chama de o peso ou a carga do ser, uma vez que o homem é ser-lançado no mundo, em condições que não escolheu, e tem diante de si possibilidades de vir a ser algo, enquanto "carregue" seu próprio ser (faça algo de sua vida, como diz Francisca acima) numa ou noutra direção. Conforme Heidegger (2006), o homem (ente humano) tem uma relação com o seu próprio ser, uma relação que exige tomada de atitudes, decisões: "Ser é o que neste ente está sempre em jogo” (Heidegger, 2006, p. 85). A cultura popular reconhece a questão do peso do ser quando manifesta o desejo de que aquele que morreu "descanse em paz" ou o conhecido RIP (Requiescat in pace).

O "aperreio" é um humor. Pode indicar rejeição da facticidade (as condições em que se é lançado) e limitação ou frustração das possibilidades. Para Heidegger (2006), o homem existe sempre em função de um poder-ser que, embora ainda não realizado, já o caracteriza de fato. Assim, uma vida que não se realiza, um poder-(querer)-ser que não se efetiva carrega a inconformidade com o próprio ser, em outras palavras, é ser o que não se quer ser.

Quando os entrevistados descrevem suas condições de vida, mostram a relação entre suas possibilidades e o mundo em que, necessariamente, todo ser humano habita. $\mathrm{O}$ relato mostra que o mundo pode se tornar um contexto inóspito (Critelli, 1996) que barra os projetos pessoais (por mais simples que sejam), deixando no horizonte da existência apenas a possibilidade última, a morte. Longe estamos de afirmar que o suicídio é inevitável, pois seria 
contrariar a realidade que todos conhecemos. Essa compreensão diz respeito aos dados apresentados e pode ser adequada a uma reflexão geral sobre o fenômeno do suicídio, talvez em acordo com a frase do dramaturgo romano Terêncio (nascido por volta de 185 a.C.): "Sou homem, nada do que é humano me é estranho".

\section{Considerações finais}

A densidade das experiências comunicadas nos impediu, neste momento, de desenvolvermos uma análise exaustiva dos conteúdos expressos pelos colaboradores, de modo que desdobramentos da pesquisa são esperados.

Os conhecimentos alcançados acerca do suicídio sinalizam para a necessidade de se continuar a abordar essa questão, uma vez que se trata de um tema associado a outros, de reconhecida importância, como saúde e qualidade de vida.

A referência à analítica existencial de Heidegger permitiu melhor aproximação ao suicídio como sendo um fenômeno relativo ao "modo de ser" do homem, sem que isso implique numa posição idealista e nem em relações mecânico-funcionais com o ambiente.

A estrutura existencial chamada por Heidegger de cura é relevante no entendimento do suicídio e merece um comentário final, com vistas a elaborações em novas publicações. Curar significa cuidar. Heidegger (2011) afirma: "A vida como cuidar vive num mundo e cuida de si nos mais diversos modos de relações e execuções correspondentes [...] em função dos objetos que se encontram na experiência e dos próprios encontros" (p. 106). A cura/ cuidado é o modo de ser de quem (o Dasein) tem uma relação com o próprio ser: "Você vivencia sua vida como sendo sua e isso significa que quem você é faz diferença para você (é uma questão para você)" (Blattner, 2006, p. 48). O fenômeno do cuidado inclui as formas deficientes de cuidar: "esse cuidar está sempre numa diretiva determinada ou indeterminada, segura ou cambaleante" (Heidegger, 2011, p. 107; grifo no original).

Entendemos que somente quem dá atenção para seu próprio ser, para o modo como vive sua vida, pode desistir de ser. É necessário dar atenção ao próprio ser, reconhecendo suas condiçóes (facticidade e possibilidades de vir a ser) e sentir (humor) o peso do ser, que esse reconhecimento possibilita, para que o suicídio se insinue na relação com o próprio ser e o cuidado se torne "cambaleante", como escreve Heidegger. Se a morte é a possibilidade da impossibilidade (Heidegger, 2006) e alguém vê a si mesmo como não tendo 
mais possibilidades, portanto, considerando-se "im-possível”, o suicídio (morte), como a possibilidade que restou, faz-se presente. Não se trata de uma fórmula matemática para o suicídio. As conclusões do trabalho, ainda em desenvolvimento, dizem respeito aos depoimentos dos entrevistados mencionados acima.

Esperamos que o conhecimento apresentado neste trabalho favoreça outros estudos que possam enriquecer o conhecimento sobre o fenômeno do suicídio e aprimorar a relação entre a Psicologia e a realidade sociocultural brasileira.

\section{Referências}

Alvarez, A. (1999). O Deus Selvagem: um estudo do suicídio. São Paulo: Companhia das Letras.

Bertolote, J. \& Fleischmann, A. (2002). A global perspective in the epidemiology of suicide. Suicidologi, 7 (2), 6-8.

Blattner, W. (2006). Heidegger's Being and Time: a reader's guide. New York: Continuum.

Boss, M. (1979). Martin Heidegger's Zollikon Seminars. Review of Existential Psychiatry and Psychology, 16, 7-20.

Brasil. Ministério da Saúde. (2006). Prevenção do suicídio: manual dirigido a profissionais das equipes de saúde mental. Brasília: Ministério da Saúde.

Cassorla, R. M. S. (1991). (org.). Do suicidio: estudos brasileiros. Campinas: Papirus.

Critelli, D. (1996). Analítica do sentido. São Paulo: Brasiliense.

Durkheim, E. (1992). O suicídio: estudo sociológico. Lisboa: Presença. (Originalmente publicado em 1897).

Dutra, E. (1997). Epidemiologia do suicídio no RN: 1985 a 1996. Anais da $50^{a}$ Reunião da Sociedade Brasileira para o Progresso da Ciência, Natal, RN.

Dutra, E. (2002). A narrativa como uma técnica de pesquisa fenomenológica. Estudos de Psicologia, 7 (2), 371-378. 
Dutra, E. (2008). Afinal, o que significa o social nas práticas clínicas fenomenológico-existenciais? Estudos e Pesquisas em Psicologia, 8 (2), 221-234.

Dutra, E. (2010). Suicídio no Brasil: estratégias de prevenção e intervenções. In: C. Hutz (Org.). Avanços em Psicologia Comunitária e intervençôes psicossociais. (pp. 223-264). São Paulo: Casa do Psicólogo.

Halling, S. \& Nill, J. (1995). A brief history of existential-phenomenological psychiatry and psychotherapy. Journal of Phenomenological Psychology, 26 (1), $1-45$.

Heidegger, M. (2011). Interpretaçôes fenomenológicas sobre Aristóteles; introdução à pesquisa fenomenológica. Petrópolis: Vozes.

Heidegger, M. (2006). Ser e tempo. Petrópolis: Vozes. (Originalmente publicado em 1927).

Maux, A. A. (2008). Do útero à adoção: a experiência de mulheres férteis que adotaram uma criança. Dissertação de Mestrado, Programa de Pós-Graduação em Psicologia, Universidade Federal do Rio Grande do Norte, Natal.

Mello-Santos, C.; Bertolote, J. \& Wang, Y. (2005). Epidemiology of suicide in Brazil (1980-2000): characterization of age and gender rates of suicide. Revista Brasileira de Psiquiatria, 27(2), 131-134.

Menninger, K. (1970). Eros e Tânatos: o homem contra si próprio. São Paulo: Ibrasa.

Qin, P.; Agerbo, E. \& Mortensen, P. (2005). Factors contributing to suicide: the epidemiological evidence from large-scale registers. In: K. Hawton (Ed.) Prevention and Treatment of Suicidal Behavior (pp. 11-28). Oxford: Oxford University Press.

Roehe, M.V. (2012). A psicologia heideggeriana. Psico, 43 (1), 14-21.

Schmidt, M. (1990). A experiência de psicólogos na comunicação de massa. Tese de Doutorado, Instituto de Psicologia da Universidade de São Paulo, São Paulo.

Silva, C.; Mateus, M. A.; Nogueira, O. \& Redondo, J. (2006). Suicídios na ópera. Leituras/Readings, 8 (5), 57-64.

World Health Organization. (2013). Health topics: suicide. Recuperado em 15 de abril, 2011, de http:/www.who.int/topics/suicide/en/. 